\title{
Sodium dependency of L-alanine absorption in canine Thiry-Vella loops ${ }^{1}$
}

BERTRAM FLESHLER ${ }^{2}$ AND RALPH A. NELSON

From Case Western Reserve University School of Medicine at Cleveland Metropolitan General Hospital, and George Scott Research Laboratory, Cleveland, Ohio, and Section of Nutrition, Mayo Foundation, Rochester, Minnesota

SUMMARY The effect of sodium on the absorption of L-alanine in vivo was tested by measuring the absorption of L-alanine from Thiry-Vella loops in dogs. Solutions containing L-alanine ( 10 or $50 \mathrm{mM}$ ) sodium at concentrations of 0,74 , or $145 \mathrm{~m}$-equiv/l and mannitol, as needed to maintain isotonicity were instilled into the loops for 10 minutes. Similar studies were done with L-alanine $50 \mathrm{mM}$ and either 0 or $145 \mathrm{~m}$-equiv/l of sodium for five minutes. Under all conditions absorption of alanine was significantly less from the solution initially free of sodium. Although these differences were statistically significant, the physiological significance was not great since the actual differences in amounts of L-alanine absorbed were small.

Insorption of sodium was low from the fluid which initially had no sodium, but exsorption proceeded rapidly and was unaffected by the luminal sodium concentration. This resulted in a rapid rise of intraluminal sodium concentration when no sodium was initially present. This persistent exsorption of sodium was, therefore, adequate to provide sodium in the lumen to activate the sodium-dependent carrier, postulated on the basis of studies in vitro. These data in vivo are consistent with the view that sodium at the intraluminal surface is important in accelerating amino acid transport, but indicate that in the absence of added intraluminal sodium the gut mucosa itself, under normal circumstances, provides the sodium needed for L-alanine absorption.

The transport of L-tyrosine and DL-phenylalanine by the isolated frog small intestine is diminished when lithium or potassium replaces sodium as the major cation in mucosal bathing solutions (Csáky, 1961). Similarly, in both rat and rabbit jejunal sacs (Harrison and Harrison, 1963; Rosenberg, Coleman, and Rosenberg, 1965), decreased transport of L-tyrosine, glycine, and methionine occurs when the sodium content is reduced in luminal solutions. Furthermore, the net transport of $\mathbf{L}$-alanine by isolated segments of rabbit ileum is markedly inhibited if sodium is replaced in the bathing solutions by choline (Field, Schultz, and Curran, 1967). Thus there exists ample evidence, based on in vitro preparations, that sodium at the mucosal surface plays a

'Supported in part by NIH grants AM 12069 and AM 08780. ${ }^{2}$ USPHS career development award 1-K3-AM-1506. significant role in the transport of amino acids into the intestinal cell.

Conditions in vivo, however, differ from those in vitro in at least two ways which could affect the interrelationship between sodium absorption and the absorption of other substances. Absorbed substances are removed from the absorbing 7 cells rather than being accumulated in the tissues. Furthermore, sodium exsorption, that is, the undirectional movement of sodium from a large pool in the body into the lumen of the intestine, can occur only in minimal amounts in the in vitro situation since the tissue is removed from the body. Because of these differences it seemed important to examine the effect of intraluminal sodium on absorption of another material under $\rightleftharpoons$ physiological conditions. The present study, therefore, was an attempt to determine in unanaes- 
thetized dogs whether the measured absorption rates of a common neutral amino acid, L-alanine, could be altered by changing the sodium content of solutions placed within chronic Thiry-Vella loops.

\section{Methods}

Using aseptic techniques, Thiry-Vella loops of the upper small intestine were constructed in seven dogs. All animals received general anaesthesia. The segments began just distal to the entrance of the pancreatic ducts and extended 25 to $30 \mathrm{~cm}$ distally. An intestinal loop consisting of duodenum and upper jejunum was resected from the intestinal tract with intact nerve and blood supply. Each stoma was brought out through the abdominal wall. Intestinal continuity was restored by end-to-end anastomosis. Following surgery a two-week period of stabilization was allowed before studies were started. The dogs ate and behaved normally. Studies were performed in the morning following an overnight fast during which free access to water was permitted. All studies were done in the conscious, well adjusted, unanaesthetized animal.

The solutions used for absorption tests contained L-alanine at concentrations of either 10 to 50 millimol. The $10 \mathrm{mM}$ concentration was chosen because it was midway between the levels shown to be sodium dependent in vitro (Curran, Schultz, Chez, and Fuisz, 1967). The greater L-alanine concentration, exceeding those of other studies, was then picked to assess the influence of sodium on L-alanine transport when the amino acid was well in excess of its blood concentration. Each concentration of L-alanine was studied at three sodium levels: 0,74 , or $140 \mathrm{~m}$-equiv/litre. Each of the three sodium concentrations, at either of the L-alanine levels, was tested in any one dog in the same morning, the order of testing being varied from day to day. Four dogs were studied at an L-alanine concentration of 10 millimol. Fourteen experiments were performed on these at each sodium concentration, a total of 42 in all. Two dogs were studied with $50 \mathrm{mM}$ L-alanine, and twelve experiments were performed at each sodium concentration, a total of 36 experiments. In solutions in which the sodium content was reduced, mannitol replaced sodium chloride in equiosmolar amounts. Tracer amounts of $\mathrm{Na}^{22}$ were added to each solution.

Absorption tests were conducted as follows. Twenty-five $\mathrm{ml}$ of solution was instilled into the loop, allowed to remain for 10 minutes and then withdrawn. Fluid remaining was estimated by rinsing the loop with $100 \mathrm{ml}$ of isotonic mannitol solution. The total activity of $\mathrm{Na}^{22}$ in the rinse (expressed as counts/sec) divided by the concentration of $\mathrm{Na}^{22}$ in the aspirate (expressed as counts $/ \mathrm{sec} / \mathrm{ml}$ ) yielded the volume of fluid not aspirated at the end of the test period. Each absorption test was separated by a thirty-minute waiting period in order to drain all residual fluid from the loops. Before each test air was carefully blown through the segments to remove any fluid which might have remained. This technique is that described by Code, Bass, McClary, Newnum, and Orvis (1960), for use in unanaesthetized animals.

In an attempt to study L-alanine absorption at lower intraluminal sodium concentrations, an additional set of tests lasting only five minutes was performed using $L$-alanine at a concentration of $50 \mathrm{mM}$ in solutions with sodium concentrations of either 0 or $140 \mathrm{~m}$-equiv/litre.

L-Alanine concentration was determined by column chromatography according to modifications of the method of Spackman, Stein, and Moore (1958) adapted for an amino acid autoanalyzer system (Piez and Morris, 1960). Sodium concentration was determined by flame photometry, and the activity of $\mathrm{Na}^{22}$ by counting in a well-type scintillation counter. Sodium fluxes were calculated by the method of Berger and Steele (1958). For solutions with an initial sodium concentration of zero, insorption was calculated by multiplying the average quantity of $\mathrm{Na}^{23}$ (non-radioactive) present in the gut lumen by the percentage of isotopes absorbed during the test period (Code et al, 1960). Exsorption was determined by difference between insorption and net transport. Net transport of L-alanine, sodium, and water was determined by the difference between the amount instilled and the total amount recovered at the end of the test period. The results were analysed by assessing the significance of mean differences between paired observations, each dog serving as its own control on each study day (Fisher, 1948). The three dogs used for the five-minute tests were different from those studied for 10 minutes. The latter had been used for a longer time. Ten five-minute experiments were performed at each sodium concentration, a total of 20 experiments.

\section{Results}

TEN-MINUTE STUDY PERIODS

\section{L-alanine absorption}

When the L-alanine concentration was $10 \mathrm{mM}$ (Table I), the absorption from the solution containing no sodium was significantly lower than from either of the solutions containing sodium. Similarly, when the L-alanine concentration was $50 \mathrm{mM}$ (Table II), alanine absorption from the solution which initially contained no sodium was also significantly lower than when sodium was present. There was no difference, however, in the amount of L-alanine absorbed, whether its 


\begin{tabular}{|c|c|c|c|c|c|c|}
\hline \multicolumn{2}{|c|}{$\begin{array}{l}\text { Intraluminal Sodium (m-equiv/l; } \\
\text { mean and range) }\end{array}$} & \multirow[t]{2}{*}{$\begin{array}{l}\text { Net Water Flux } \\
(\mathrm{ml} / 10 \text { min; mean } \pm S E)\end{array}$} & \multicolumn{3}{|c|}{$\begin{array}{l}\text { Sodium Flux } \\
(\mu E q / 10 \text { min; mean } \pm S E)\end{array}$} & \multirow[t]{2}{*}{$\begin{array}{l}\text { L-Alanine Absorbed } \\
(\mu M / 10 \text { min; mean } \pm S E)\end{array}$} \\
\hline Initial & Final & & Insorption. & Exsorption & Net & \\
\hline $\begin{array}{l}0 \\
74 \quad(72-77) \\
145(141-149)\end{array}$ & $\begin{array}{cl}42 & (31-70) \\
93 & (72-105) \\
147 & (140-154)\end{array}$ & $\begin{array}{l}-2.8 \pm 0.7^{1} \\
-0.4 \pm 0.7^{2} \\
-0.5 \pm 0.7^{2}\end{array}$ & $\begin{array}{c}217 \pm 34 \\
1008 \pm 110^{8} \\
1345 \pm 122^{3,4}\end{array}$ & $\begin{array}{l}1402 \pm 160 \\
1386 \pm 175 \\
1318 \pm 70\end{array}$ & $\begin{array}{c}-1285 \\
-378 \\
27\end{array}$ & $\begin{array}{l}140 \pm 40 \\
190 \pm 50^{2} \\
180 \pm 50^{5}\end{array}$ \\
\hline
\end{tabular}

Table I Sorption in the canine small intestine when the initial concentration of L-alanine was $10 \mathrm{mM}$ (10-minute tests)

${ }^{1}$ Negative values refer to gain in gut contents

'Significantly different from value for initial solution, where $\mathrm{Na}=0$ at $\mathrm{P}<0.02$

${ }^{3}$ Significantly different from value for initial solution, where $\mathrm{Na}=0$ at $\mathrm{P}<0.01$

SSignificantly different from value for initial solution, where $\mathrm{Na}=74$ at $\mathrm{P}<0.01$

Significantly different from value for initial solution, where $\mathrm{Na}=0$ at $\mathrm{P}<0.05$

\begin{tabular}{|c|c|c|c|c|c|c|}
\hline \multicolumn{2}{|c|}{$\begin{array}{l}\text { Intraluminal Sodium (m-equiv/l; } \\
\text { mean and range) }\end{array}$} & \multirow[t]{2}{*}{$\begin{array}{l}\text { Net Water Flux } \\
(\mathrm{ml} / 10 \text { min; mean } \pm S E)\end{array}$} & \multicolumn{3}{|c|}{$\begin{array}{l}\text { Sodium Flux } \\
(\mu E q / 10 \text { min; mean } \pm S E)\end{array}$} & \multirow[t]{2}{*}{$\begin{array}{l}\text { L-Alunine Absorbed } \\
(\mu M / 10 \text { min; mean } \pm S E)\end{array}$} \\
\hline Initial & Final & & Insorption & Exsorption & Net & \\
\hline $\begin{array}{l}0 \\
74(73-76) \\
143(144-147)\end{array}$ & $\begin{array}{cc}41 & (30-51) \\
92 & (85-96) \\
145 & (142-148)\end{array}$ & $\begin{aligned}-2.5^{1} & \pm 0.5 \\
-1.1 & \pm 0.8^{2} \\
5.1 & \pm 1.1^{3.4}\end{aligned}$ & $\begin{array}{c}234 \pm 27 \\
946 \pm 139^{3} \\
2045 \pm 183^{3,4}\end{array}$ & $\begin{array}{l}1375 \pm 815 \\
1601 \pm 153 \\
1786 \pm 97^{3}\end{array}$ & $\begin{array}{r}-1141 \\
-\quad 655 \\
259\end{array}$ & $\begin{array}{l}600 \pm 18 \\
800 \pm 20^{2} \\
920 \pm 180^{3}\end{array}$ \\
\hline
\end{tabular}

Table II Sorption in the canine small intestine when the initial concentration of L-alanine was $50 \mathrm{mM}$ (10-minute tests)

${ }^{1}$ Negative values refer to gain in gut contents

'Significantly different from value for initial solution, where $\mathrm{Na}=0$ at $\mathrm{P}<0.05$

'Significantly different from value for initial solution, where $\mathrm{Na}=0$ at $\mathrm{P}<0.01$

'Significantly different from value for initial solution, where $\mathrm{Na}=74$ at $\mathrm{P}<0.01$

\begin{tabular}{|c|c|c|c|c|c|c|}
\hline \multicolumn{2}{|c|}{$\begin{array}{l}\text { Intraluminal Sodium (m-equiv/l; } \\
\text { mean and range) }\end{array}$} & \multirow[t]{2}{*}{$\begin{array}{l}\text { Net Water Flux } \\
(\mathrm{ml} / 10 \text { min; mean } \pm S E)\end{array}$} & \multicolumn{3}{|c|}{$\begin{array}{l}\text { Sodium Flux } \\
(\mu E q / 10 \text { min; mean } \pm S E)\end{array}$} & \multirow[t]{2}{*}{$\begin{array}{l}\text { L-Alanine Absorbed } \\
(\mu M / 10 \text { min; mean } \pm S E)\end{array}$} \\
\hline Initial & Final & & Insorption & Exsorption & Net & \\
\hline $\begin{array}{l}0 \\
140(139-141)\end{array}$ & $\begin{array}{c}29(24-39) \\
141(137-146)\end{array}$ & $\begin{array}{l}0 \cdot 8 \pm 5 \cdot 0 \\
5 \cdot 0 \pm 0.6^{2}\end{array}$ & $\begin{array}{r}160 \pm 15 \\
1329 \pm 66^{2}\end{array}$ & $\begin{array}{l}857 \pm 61 \\
708 \pm 71\end{array}$ & $\begin{array}{l}-697^{1} \\
621\end{array}$ & $\begin{array}{l}560 \pm 30 \\
690 \pm 14^{3}\end{array}$ \\
\hline
\end{tabular}

Table III Sorption in the canine small intestine when the initial concentration of L-alanine was $50 \mathrm{mM}$

(five-minute tests)

${ }^{1}$ Negative values refer to gain in gut contents

${ }^{2} \mathrm{p}<0.01$

${ }^{3} P<0.05$

concentration was 10 or $50 \mathrm{mM}$, when absorption from each of the two solutions with sodium was compared. Despite reduced amino acid transport when the initial sodium concentration was zero, the absolute amount of L-alanine absorbed was still $74 \%$ and $63 \%$ (for the 10 and $50 \mathrm{mM}$ L-alanine concentrations respectively). These percentages express the ability of the gut to absorb the amino acid when the sodium concentration in the initial luminal fluid was 140 m-equiv/litre. The amount of L-alanine absorbed from all test solutions was four to five times higher when its initial concentration was $50 \mathrm{mM}$ than when the initial concentration was $10 \mathrm{mM}$.

Sodium concentration changes and fluxes

There was a marked secretion of body sodium into the gut lumen when the initial fluid was free of sodium. This produced a prompt rise in luminal sodium concentration. The smallest increase observed at the end of a test was $\mathbf{3 0}$ m-equiv/litre. A net shift of sodium into the luminal fluid also occurred when the initial sodium concentration was 74 m-equiv/l, which also increased the luminal sodium concentration. Absorption of sodium occurred in those solutions initially at $145 \mathrm{~m}$-equiv/l, but there was nochange in luminal concentration.

Exsorption was relatively constant despite wide differences in initial intraluminal sodium or L-alanine concentrations. Insorption rates for sodium, by contrast, were significantly lower from the solutions initially free of sodium. At the $10 \mathrm{mM}$ L-alanine level, insorption was increased only slightly when the initial sodium concentration was increased from 74 to $145 \mathrm{~m}$-equiv/l whereas at $50 \mathrm{mM}$ L-alanine the increase in sodium insorption was much more marked.

\section{Water movement}

When the initial sodium concentration was zero, secretion of water from the body pool into the gut lumen occurred, and when the initial sodium 
concentration was $74 \mathrm{~m}$-equiv/l, body water also entered the lumen, but to a lesser extent. The secretion of water was in reverse proportion to the absorption when the sodium absorption was greater. This occurred when the initial sodium concentration was $140 \mathrm{~m}$-equiv/litre.

\section{FIVE-MINUTE STUDY PERIODS}

\section{L-alanine absorption}

Significantly less L-alanine was absorbed when no sodium was initially present in nine of 10 paired tests in three dogs studied (Table III). The absolute amount of L-alanine absorbed when the initial sodium concentration was zero, however, was $81 \%$ of that absorbed when the sodium concentration was $140 \mathrm{~m}$-equiv/litre.

\section{Sodium concentration changes and fluxes}

The lowest sodium concentration in any animal at the end of the study was 24 m-equiv/litre. Thus, as in the ten-minute tests, there was a marked shift of body sodium into the gut luminal solutions initially free of sodium. Exsorption was again constant for both test fluids but insorption varied markedly and directly with the concentration of sodium in the luminal contents.

\section{Water movement}

The general pattern of the relationship of water to sodium movement was similar to that observed in the 10-minute tests. It was lower, virtually zero, however, for the solution, originally free of sodium, in which the net sodium shift was negative.

\section{Discussion}

These results of studies in vivo are consistent with the view that L-alanine transport by the gut is dependent, at least in part, on the presence of sodium in the intraluminal fluid. Since these findings were similar for initial $\mathbf{L}$-alanine concentrations of 10 or $50 \mathrm{mM}$ the data indicated that the dependency of L-alanine absorption on sodium transport is operative over a wide range of the concentration of the amino acid.

Although the differences noted in the results were statistically significant, the actual differences in the amounts of L-alanine absorbed were relatively small. Under all the conditions studied, gut absorption of L-alanine was extremely efficient.

A sodium-dependent carrier system for sugars and amino acids has been described (Crane, 1965; Crane, Forstner, and Eicholz, 1965) and our results can be interpreted in terms of such a system. It is possible, however, that, along with such an interpretation, absorption of the amino acid by the process of solvent drag was also operative as a mode of alanine transport. Our results showed that as sodium absorption increased, water absorption also increased. Our data indicated, however, that increased water absorption did not increase alanine absorption. (A change from secretion of water of $1 \mathrm{ml}$ to an absorption of water of $5 \mathrm{ml}$ (Table II) did not affect alanine absorption.) Since active transport of L-alanine has been demonstrated under a variety of conditions (Curran et al, 1967; Field et al, 1967; Fleshler, Butt, and Wismar, 1966), these findings of water transport, if it does influence alanine absorption, is probably passive in nature. Schultz, Curran, Chez, and Fuisz (1967) have demonstrated, however, that alanine is transported by the carrier system in the absence of luminal sodium, although transport is faster when sodium is present. In our studies, increased water movement could have facilitated this process, but if it did, its effect was not great.

The purpose of this study was to examine the relationship between sodium and L-alanine transport by the gut in vivo. However, it was not possible to study the absorption of L-alanine under circumstances in which the intraluminal fluid contained either no sodium or constant very low sodium levels. Exsorption of sodium in each of the circumstances tested continued at a rate which raised intraluminal sodium concentrations to a level of at least 24 m-equiv/l, even in the five-minute tests. A comparison of the five- and 10-minute studies showed increased L-alanine absorption from both sodium concentrations ( 0 and 140 m-equiv/l) tested. There was, however, only a significant increase in L-alanine absorption $(\mathrm{p}<0.01)$ at 10 minutes when the initial sodium concentration was in the range of $140 \mathrm{~m}$-equiv/litre. The failure to demonstrate consistently greater absorption over a 10-minute period compared with a five-minute period could be due to differences in the surface areas available for absorption. Intestinal segments were constructed as similarly as possible in all the dogs, but to create loops exactly equal in size is extremely difficult. As noted above different dogs were used in the five- and 10-minute tests. Furthermore, the loops for the 10-minute studies were utilized for longer periods and may have shortened more than those used in the fiveminute tests. In addition to these probable differences in absorbing surfaces there exists the possibility that at zero sodium conditions insufficient sodium was present even at 10 minutes to saturate the system and provide optimal amino acid absorption. When, however, sufficient sodium was present to saturate the carrier, absorption was greater at 10 minutes.

Under the conditions of this study sodium exsorption appeared independent of the concentrations of either sodium or of other substances in the intraluminal fluid. The situation in vivo reported here, and presumably normally operative, is thus somewhat similar to experiment C 
(Table II) the in vitro preparation of the rabbit ileum in Schultz et al (1967). Sodium in this experiment left the cell and entered a non-sodiumcontaining bathing solution. This provided, to a fair degree, the sodium necessary for alanine influx. Under physiological conditions in the conscious animal, exsorption of sodium was steady, rapid, and extremely efficient. Thus it was unnecessary to provide sodium in the intraluminal fluid. The gut promptly provided it from the larger pool available in the body.

Another difference, in addition to the profound exsorption of sodium, existed between the in vitro and in vivo studies. In vitro, an increased L-alanine concentration produced an increased sodium influx (Curran et al, 1967). Increasing L-alanine concentration and L-alanine absorption, in vivo, resulted in greater sodium insorption only when the initial concentration of sodium was 145 m-equiv/litre. When the initial sodium concentration was either zero or $74 \mathrm{~m}$-equiv/l, sodium insorption appeared to be unrelated to either L-alanine concentration or absorption rate.

It is of interest that the critical intraluminal sodium concentration requirement in these studies was in the range of 40-70 m-equiv/litre. (This estimate was based on the sodium concentration achieved at the end of the test period in studies with solutions initially free of sodium.) The data of Crane et al (1965) on the accumulation of 6-deoxyglucose by hamster gut sacs in vitro, and of Harrison and Harrison (1963) on the accumulation of L-tyrosine by rat everted small intestine in vitro, suggest that in vitro a similar sodium concentration is required for the transport of these substances. Additional increments of sodium, both in our studies and those cited, have relatively little further effect in promoting absorption. This intraluminal sodium concentration is obviously easily supplied under normal circumstances by exsorption by the gut.

We have previously reported (Fleshler et al, 1966) perfusion studies in humans indicating that glycine and L-alanine absorption proceeded at normal rates even when sodium was not added to the perfusate. Since sodium entered the gut lumen promptly, it was suggested that the concentration of sodium required was probably low, and that endogenous sodium was presumably present in sufficient amounts. The present studies support this idea. Recently Olsen and Ingelfinger (1968) reported that an effect of sodium on glucose absorption in man could be demonstrated only at low luminal glucose concentrations and that at luminal concentrations where 'downhill' transport from gut to blood might be expected, no effect was observed. Our experiments with L-alanine differ, since relative sodium-dependency, in the sense that L-alanine absorption was increased from those solutions which contained sodium, was demonstrated at concentrations of L-alanine exceeding that found in blood. It is possible that the sodium-dependent carrier behaves differently in relation to glucose than it does to amino acid, since these findings of relative sodium dependency over a range of L-alanine concentrations are in agreement with results of in vitro experiments (Curran et al, 1967).

\section{References}

Berger, E. Y., and Steele, J. M. (1958). The calculation of transfer rates in two compartment systems not in dynamic equilibrium. J. gen. Physiol., 41, 1135-1152.

Code, C. F., Bass, P., McClary, G. B., Jr., Newnum, R. L., and Orvis, A. L. (1960). Absorption of water, sodium, and potassium in small intestine of dogs. Amer. J. Physiol., 199, 281-288.

Crane, R. K. (1965). $\mathrm{Na}^{+}$-dependent transport in the intestine and other animal tissues. Fed. Proc., 24, 1000-1006.

Crane, R. K., Forstner, G., and Eicholz, A. (1965). Studies on the mechanism of the intestinal absorption of sugars. $X$. An effect of $\mathrm{Na}^{+}$concentration on the apparent Michaelis constants for intestinal sugar transport, in vitro. Biochim. biophys. Acta (Amst.), 109, 467-477.

Csàky, T. Z. (1961). Significance of sodium ions in active intestinal transport of nonelectrolytes. Amer. J. Physiol., 201, 9991001 .

Curran, P. F., Schultz, S. G., Chez, R. A., and Fuisz, R. E. (1967). Kinetic relations of the Na-amino acid interaction at the mucosal border of intestine. J. gen. Physiol., 50, 1261-1286.

Field, M. Schultz, S. G., and Curran, P. F. (1967). Alanine transport across isolated rabbit ileum. Biochim. biophys. Acta (Amst.), 135, 236-243.

Fisher, R. A. (1948). Statistical Methods for Research Workers. 10th ed. Edinburgh, Oliver and Boyd. Hafner, New York.

Fleshler, B., Butt, J. H., and Wismar, J. D. (1966). Absorption of glycine and L-alanine by the human jejunum. $J$. clin. Invest., 45, 1433-1441.

Harrison, H. E., and Harrison, H. C. (1963). Sodium, potassium, and intestinal transport of glucose, l-tyrosine, phosphate, and calcium. Amer. J. Physiol., 205, 107-111.

Olsen, W. A., and Ingelfinger, F. J. (1968). The role of sodium in intestinal glucose absorption in man. J. clin. Invest., 47, 1133-1142.

Piez, K. A., and Morris, L. (1960). A modified procedure for the automatic analysis of amino acids. Analyt. Biochem., 1, 187-201.

Rosenberg, I. H., Coleman, A. L., and Rosenberg, L. E. (1965). The role of sodium ion in the transport of amino acids by the intestine. Biochim. biophys. Acta (Amst.), 102, 161-171.

Schultz, S. G., Curran, P. F., Chez, R. A., and Fuisz, R. E. (1967). Alanine and sodium fluxes across mucosal border of rabbit ileum. J. gen. Physiol., 50, 1241-1260.

Spackman, D. H., Stein, W. H., and Moore, S. (1958). Automatic recording apparatus for use in the chromatogiaphy of amino acids. Analyt. Chem., 30, 1190-1206. 